\title{
Impact of Window Operation Behaviours on Cooling Load of High-rise Residential Buildings in Hong Kong
}

\author{
Jia Du${ }^{1}$, Wei Pan ${ }^{1}$ \\ ${ }^{1}$ The University of Hong Kong, Hong Kong S.A.R. ,China
}

\begin{abstract}
Energy saving can be achieved with proper natural ventilation from window opening. Window operation behaviours affect the cooling load by introducing fresh air and interacting with the operation of air conditioners. However, there is limited knowledge on how window operation behaviours influence the cooling load in highrise buildings. This paper thus examines quantitatively the impact of window operation on cooling load. The research was conducted through building simulation compared with a post-occupancy evaluation survey with a 40-storey typical high-rise residential building in Hong Kong. The results reveal up to $11 \%$ variance of cooling load among the residential flats with different window operation behaviours.
\end{abstract}

\section{Introduction}

Buildings are important energy consumers and carry massive energy saving potential with implementation of best energy-saving technologies and energy efficiency policies (IEA \& IPEEC, 2015). Cooling contributes largely to the total energy consumption of buildings. Cooling accounts for one quarter of the total residential building energy consumption in Hong Kong, a subtropical city with high ambient temperature and long cooling season (EMSD, 2018). Natural ventilation through window opening can affect cooling energy consumption. Previous research reported that the natural ventilation from windows in subtropical cities could achieve remarkable energy savings via optimized operation modes in spring and autumn (Bayoumi, 2017). The window operation behaviours can affect the cooling load in a residential flat in two ways, firstly the introduction of fresh air and secondly the interaction with operation of air conditioners. However, it remains largely unknown how the occupant behaviours of opening windows and operating air conditioners interact with each other and how the behaviours change the cooling load.

In addition, the increasing population has given birth to megacities since the beginning of last century. There are more and more "City of Towers" with high-rise buildings as dominant building type around the world. The height of building introduces uncertainty into the energy performance of flats in high-rise buildings by climatic factors, including the outdoor air temperature and the wind speed. On-site measurement from literature review in Malaysia (Aflaki, Mahyuddin, \& Baharum, 2016) observed higher indoor wind speed and lower indoor air temperature in the living rooms at Floor 13 compared to those at Floor 3. The fact indicated energy conservation opportunities of high-rise residential buildings and flats at higher floors might take less effort to maintenance a satisfactory indoor environment. Highrise buildings can indeed benefit in energy performance from the wind factor as shown by simulation results (Lotfabadi, 2014). However, limited research paid attention to how the cooling load changed with behavioural and climatic factors in high-rise residential buildings.

Based on the two research gaps above, this paper aims to examine operation behaviours of window and air conditioner in high-rise residential buildings and their impacts on cooling load. The research has been carried out with a case study of a typical high-rise residential building in Hong Kong. It comparatively analyses cooling load intensity of flats at ten floors, from six orientations, with four various behaviour modes of window operation. The findings expand existing knowledge about occupant behaviours for cooling in residential buildings and inform future research on energy efficiency of high-rise buildings.

\section{Methodology}

The research framework is elaborated in Figure 1. The research was carried out through building modeling and energy simulation of a typical 40-storey high-rise residential building in Kowloon, Hong Kong.

Firstly, a questionnaire survey was conducted with the residents to collect data about occupant behaviour modes. The survey results provided behaviour parameters to the energy model. Secondly, a building energy model using DeST software was established based on the geometrical information of the building. Related inputs were obtained from the building information modelling (BIM) documentation of the building. Thirdly, multiple methods were employed to identify climatic parameters of the energy model. The Typical Meteorological Year (TMY) was used to acquire the climate data of Hong Kong. The CFD model by Phoenics software was used to simulate the wind pressure. Moreover, the Dry Adiabatic Lapse Rate (DALR) method was used to process the ambient temperature. Then the building energy model with comprehensive inputs of behaviour and climatic 
parameters was validated with related energy use data from the questionnaire survey. Finally, the energy model calculated the hourly cooling load throughout the cooling season for future analysis.

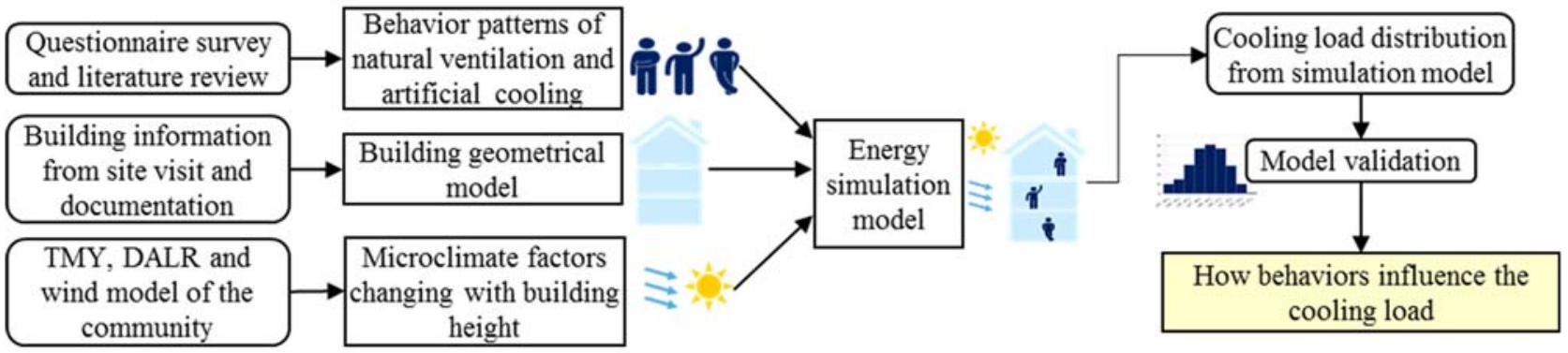

Figure 1: Research framework

\section{Data collection and modelling}

\section{Behaviour information}

Behaviour information serves as inputs of the energy model in several aspects: daily routine of residents, operation mode of windows, operation mode of air conditioners, cooling season, air conditioned area of flats, and the relationship between behaviours with window opening and air conditioner operating. In addition, the energy consumption data in terms of monthly energy bills of households was collected for the validation of the energy model.

An on-site questionnaire survey was conducted among 988 households of the target high-rise building, namely Building $\mathrm{X}$. Question text and answer type were carefully designed with reference to existing sophisticated survey mechanism (Bethlehem, 2009; Leeuw, Hox, \& Dillman, 2008; Simone et al., 2018; Thompson, 2012). A pilot study was employed to improve the questionnaire. The recruitment was taken at the entrance of the building X. Every passers were able to participate voluntarily. Researchers would be right beside the participants during the survey, to make sure they understand the questions and give the right answers. Finally, 135 well-filled copies were received. The surveyed families was averagely distributed in different storeys and family sizes, avoiding as much as possible bias in sampling. The behaviour information acquired from the survey results are elaborated below.

Typical daily routine of working people and unemployed people were summarized from the survey results, shown in Figure 2 (Du \& Pan, 2018). The occupied schedule informed settings of human load and ticked out the period accessible to artificial cooling.

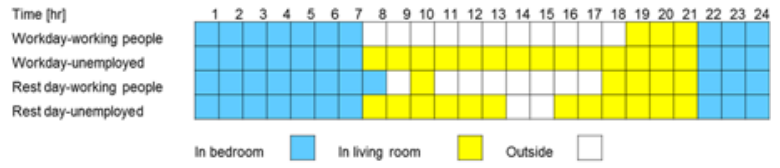

Figure 2 Daily routine of occupants

Window opening and closing are motivated by both thermal and time drivers (Hong, Taylor-Lange, D'Oca, Yan, \& Corgnati, 2016). Influencing factors of window opening considered in this paper are time of day and outdoor air temperature, according to existing window opening models (Balvedi, Ghisi, \& Lamberts, 2018; Stazi, Naspi, \& D'Orazio, 2017). In the survey in Hong
Kong, researchers asked about operation hours in a typical day of windows in the living room, bedroom and kitchen separately. Four popular schedules of window opening were summarized in Table 1, varying in the duration and the start time of the operation behaviour. Actually, the majority operation mode of window at proportion of $40 \%, 33 \%$ and $47 \%$ for the living room, bedroom and kitchen, was always keeping windows on, with an open grade of half-open. The thermal driver was defined as the up limit of outdoor air temperature when opening window. The up limit was set as $26^{\circ} \mathrm{C}$, considering both thermal comfort of occupants and climate conditions of Hong Kong.

Table 1: Operation schedule of windows

\begin{tabular}{|c|l|}
\hline Item & \multicolumn{1}{|c|}{ Description } \\
\hline Case 1 & Never open windows \\
\hline Case 2 & Open windows in the morning during 6:00 7:59 \\
\hline Case 3 & Open windows during daytime, 6:00 17:59 \\
\hline Case 4 & Always keep windows open \\
\hline
\end{tabular}

The cooling season in Hong Kong started from May and finished after October according to the operation period of air conditioners reported by the survey. Living rooms and bedrooms were well air conditioned with window type air conditioners or split type air conditioners. The majority of occupants would turn on air conditioners when feeling hot and close them when feeling cold. The set point temperature generally ranging from $17^{\circ} \mathrm{C}$ to $27^{\circ} \mathrm{C}$. It is also suggested by the government to set and maintain air-conditioned room temperature between $24^{\circ} \mathrm{C}$ and $26^{\circ} \mathrm{C}$ in summer for families (EEO \& EMSD, 2017). Thus, the thermostat temperature of cooling was set as $26^{\circ} \mathrm{C}$ and the up limit temperature of tuning on air conditioners in the model was set as $27^{\circ} \mathrm{C}$.

In addition, the exclusionary relationships between window and air-conditioner operation were obvious, with more than $80 \%$ occupants stated that they would not opening window and operating air conditioner at the same time. The interaction between two behaviours will be discussed later.

\section{Climatic parameters}

Three climatic parameters considered in this paper are wind speed, outdoor dry bulb air temperature, relative humidity. Different sets of climate data were applied in the simulation of flats at different floors. 
- Wind speed and pressure

Average wind speed of 16 directions were available in the Typical Meteorological Year (TMY) calculated by researchers in Hong Kong (Chan, Chow, Fong, \& Lin, 2006) The raw wind data was measured with an anemometer at $90 \mathrm{~m}$ above sea level in the Hong Kong Observatory. The change of wind speed $\left(v_{H}, \mathrm{~m} / \mathrm{s}\right)$ in line with height was calculated with the Hellmann exponential law, equation (1), which was commonly used by researchers to correlate the wind speeds of two heights.

$$
v_{H}=v_{m e t} \times\left(\frac{H}{H_{m e t}}\right)^{\alpha}
$$

The friction coefficient $\alpha$ is set as 0.35 for urban city with many high-rises such as Hong Kong ( $\mathrm{Ng}$, Yuan, Chen, Ren, \& Fung, 2011), where $v_{m e t}(\mathrm{~m} / \mathrm{s})$ is the reported wind speed by the TMY data at the height $H_{\text {met }}$ (m), and $H(\mathrm{~m})$ is the height of measured point changing with the floor of the flat. The wind speed from 16 wind directions can be different and this issue was carefully considered in the wind model.

In addition, wind pressure coefficients of windows were input parameters of building energy model employing DeST Vent + , the simulation tool of natural ventilation. Wind pressure coefficient $C_{P}$ (unit: 1 ) was calculated by equation (1) and (2), shown below:

$$
C_{P}=\frac{P_{S}}{P_{V}}=\frac{P_{S}}{\frac{1}{2} \times \rho \times v_{H}^{2}}
$$

where $P_{S}(\mathrm{~Pa})$ is wind pressure at the measured point from a CFD model by the Phoenics software, $P_{V}(\mathrm{~Pa})$ is the dynamic pressure calculated with air density $\rho$ $\left(\mathrm{kg} / \mathrm{m}^{3}\right)$ set as $1.2 \mathrm{~kg} / \mathrm{m}^{3}$ and wind speed in the freestream $v_{H}(\mathrm{~m} / \mathrm{s})$ calculated from equation (1) at the height of the measured point.

The Phoenics model contained main obstacles within $200 \mathrm{~m}$ from the $125 \mathrm{~m}$-high Building $\mathrm{X}$ (the red circled block), shown in Figure 3. The calculation domain was set as $2000 \mathrm{~m} \times 2000 \mathrm{~m} \times 500 \mathrm{~m}$ with the community in the centre, carefully considering the estimated $157 \mathrm{~m}$ recirculation zone. Wind pressure coefficients of 16 directions for windows of flats at different height were then calculated with the wind model and equations. Figure 4 displays simulation results of wind pressure from the direction of east.

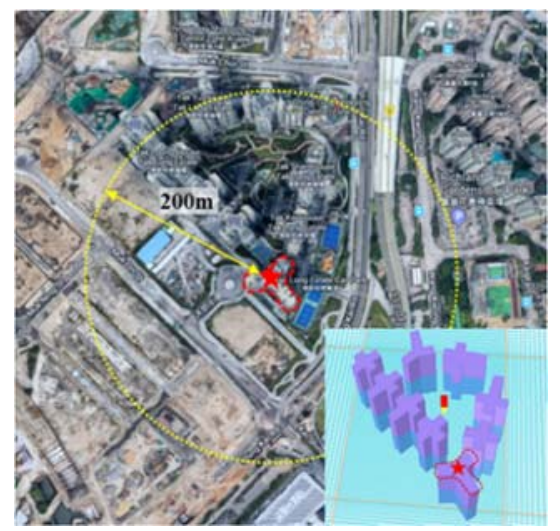

Figure 3: Phoenics model of Building $X$

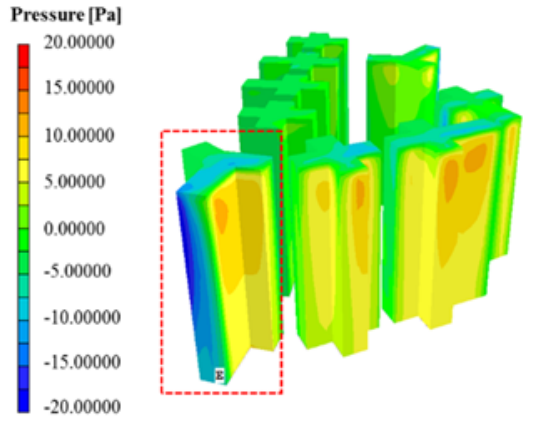

Figure 4: Simulation results of pressure on the surface of Building $X$

- Air temperature

The change of outdoor air temperature in line with height was calculated with the Dry Adiabatic Lapse Rate (DALR). DALR method was applied (Lotfabadi, 2014) in research about skyscrapers in Iran, and the dry bulb temperature changed linearly with the measured point, expressed as:

$$
\Gamma=-\frac{d T}{d H}=\frac{g}{C_{p}}
$$

where $\mathrm{T}\left({ }^{\circ} \mathrm{C}\right)$ is temperature at $\mathrm{H}(\mathrm{m})$ altitude, $C_{p}$ $(\mathrm{J} /(\mathrm{kg} \cdot \mathrm{K}))$ is the specific heat at constant pressure, $\mathrm{g}$ $\left(\mathrm{m} / \mathrm{s}^{2}\right)$ is the standard gravity and $\Gamma(\mathrm{K} / \mathrm{m})$ is the adiabatic lapse rate. Finally, according to data from upper-air observations (Hong Kong Observatory, 2018), the value of $\Gamma$ was set as $8^{\circ} \mathrm{C} / \mathrm{km}$.

\section{- Relative humidity}

The relative humidity of outdoor air does not change much according to record of Hong Kong Observatory, e.g. observed as $81 \%$ at $66 \mathrm{~m}$ above the sea level and $82 \%$ at $168 \mathrm{~m}$ on $1^{\text {st }}$ August 2018 at $22.32 \mathrm{~N}, 114.17 \mathrm{E}$ the King's Park Meteorological Station. Thus, the limited change of relative humidity with height can be ignored in this building energy model, where the object is within $130 \mathrm{~m}$ above the sea level.

\section{Building energy model}

The Building $\mathrm{X}$ is a Y-shaped $125 \mathrm{~m}$-high residential building with 40 residential floors. Building geometrical information was available in BIM documentation. The highlighted Flat $\mathrm{A} \sim \mathrm{F}$ of the same layouts, at Floor $3,7,11,15,19,23,27,31,35,39$ were selected as research subjective as shown in Figure 5. Typical floors, ground floor and top floor were built with the DeST software for energy simulation (Figure 6).

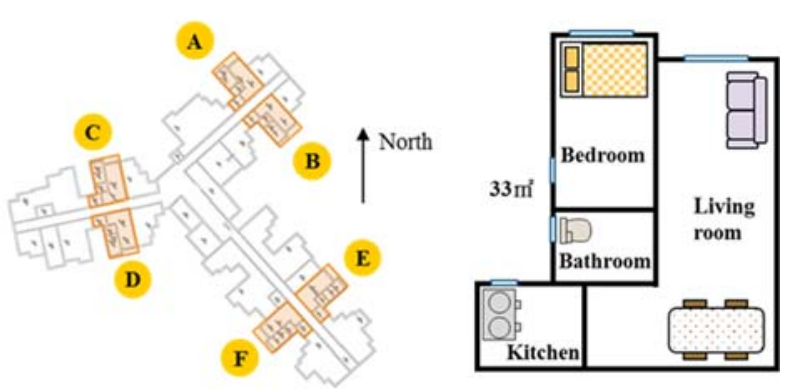

Figure 5: Geometrical model of Building X 


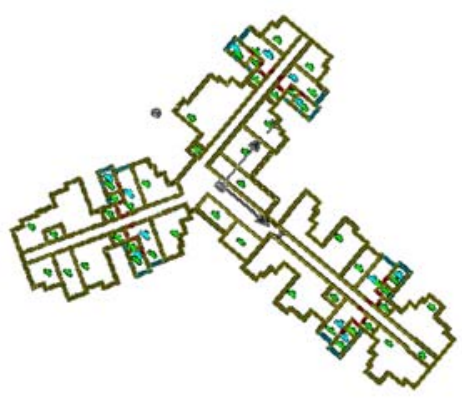

Figure 6: DeST model of Building $X$

Building façade materials were set according to experiences with windows as single layer glass, $\mathrm{U}=$ $5.7 \mathrm{~W} / \mathrm{m}^{2} \mathrm{~K}$; the internal walls as $180 \mathrm{~mm}$ ceramsite wall, $\mathrm{U}=1.515 \mathrm{~W} / \mathrm{m}^{2} \mathrm{~K}$; and the external walls as $200 \mathrm{~mm}$ concrete wall, $\mathrm{U}=0.622 \mathrm{~W} / \mathrm{m}^{2} \mathrm{~K}$.

\section{- Operation settings}

Operation settings relating to cooling load include lighting, plug-in appliances, and occupancy schedule of rooms (Table 2), in addition to behaviour modes of air conditioning and window opening discussed above. The power density of lights and devices were calculated from the appliance list obtained from the survey. The occupancy schedule of the subjective flat was defined from a typical daily routine of a family with two working adults and one child. Default inputs were kept for the unmentioned settings.

Table 2: Operation settings of the model

\begin{tabular}{|c|c|}
\hline Item & Description \\
\hline Lighting & $\begin{array}{l}\text { The peak load of lights in the living room } \\
\text { (L) and bedroom (B) is } 40 \mathrm{~W} \text {. } \\
\text { Operation schedules are on weekdays L } \\
\text { 18:00-20:59/ B 21:00-0:00 and at the } \\
\text { weekend L 17:00-20:59/ B 21:00-0:00. }\end{array}$ \\
\hline Appliances & $\begin{array}{l}\text { The peak load of plug-ins in the living room } \\
\text { is } 390 \mathrm{~W} \text { during 18:00-18:59 every day. } \\
\text { The peak load of plug-ins in kitchen is } \\
48 \mathrm{~W} \text {. }\end{array}$ \\
\hline $\begin{array}{l}\text { Occupancy } \\
\text { schedule }\end{array}$ & $\begin{array}{l}\text { On weekdays L 18:00-20:59/ B 21:00-6:59 } \\
\text { and at the weekend L 9:00-9:59, 17:00- } \\
\text { 20:59/ B 21:00-7:59. }\end{array}$ \\
\hline $\begin{array}{l}\text { Window } \\
\text { opening }\end{array}$ & $\begin{array}{l}\text { Operation schedules are shown in Table } 1 \text {. } \\
\text { The up limit of outdoor air temperature } \\
\text { when opening window is } 26^{\circ} \mathrm{C} \text {. } \\
\text { During the operation schedule, windows } \\
\text { will be open when outdoor air temperature } \\
\text { is below } 26^{\circ} \mathrm{C} \text { and would be closed when } \\
\text { outdoor air temperature is above } 26^{\circ} \mathrm{C} \text {. }\end{array}$ \\
\hline $\begin{array}{c}\text { Air } \\
\text { conditioning }\end{array}$ & $\begin{array}{l}\text { Cooling season is } 1^{\text {st }} \text { May to } 31^{\text {st }} \text { Oct. } \\
\text { Available only when the room is occupied. } \\
\text { The thermostat temperature of cooling is } \\
26^{\circ} \mathrm{C} \text { and the up limit temperature of tuning } \\
\text { on air conditioners is } 27^{\circ} \mathrm{C} \text {. }\end{array}$ \\
\hline
\end{tabular}

- Model validation

The building energy model was validated with related survey data from families with similar cooling modes. Monthly electrical bills self-reported by the participants were converted to electrical energy consumption data referring to energy price of suppliers (CLP, 2017). The monthly electricity consumption added up to an annual one. Then the electrical consumption in cooling was estimated for some interviewed families. These families had similar air-conditioning operation modes as set in the building energy model. The cooling load was a result of the total annual electricity consumption multiplied by the ratio of cooling in electricity consumption of the enduses (EMSD, 2018) and multiplied again by the coefficient of performance (COP) (Electrical and Mechanical Services Department, 2018). The cooling load estimated from the survey data was averagely 2453 $\mathrm{kWh} /$ year/ per household, and outputs of the model was averagely $2233 \mathrm{kWh} /$ year/ per household. Meanwhile, the operation mode of air conditioners set in the model is energy-efficient: with higher thermostat temperature and with preference to utilize natural ventilation other than artificial cooling. The $9 \%$ difference is thus acceptable and the model is reliable for future analysis.

\section{Results}

Cooling load of six flats (Flat A F, Figure 5) at ten floors (Floor 3 39) with four various operation modes (Never on $\sim$ Always on, Table 1) of windows were calculated by the validated building energy model. The climatic parameters of ten floors were individually set according to the change of building height. Finally, results of cooling load of 240 cases were compared and discussed on how the wind operation modes affect the cooling load.

\section{Orientation}

Firstly, six flats of the same flat type in the Y-shaped building were selected to discuss the impact of orientation on cooling load. Results of cooling load when always keeping the window open, of Flat $\mathrm{A} \sim \mathrm{F}$ at Floor 3 were illustrated in Figure 7, ranging from $47.7 \mathrm{kWh} / \mathrm{m}^{2}$ to $51.8 \mathrm{kWh} / \mathrm{m}^{2}$. The difference of cooling load among flats caused by the orientation was around $10 \%$. Orientation of flats also influenced how much the building height and window operation mode affect the cooling load. For instance, the cooling load of Flat $\mathrm{C}$ did not change with window operation modes as much as other flats, because there were generally less wind around Flat $\mathrm{C}$ according to the climate data of Hong Kong.

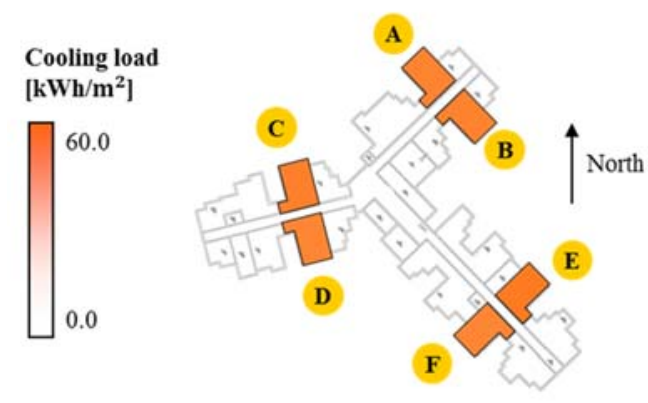

Figure 7: Cooling load of Floor 3 in case 4

Considering the accessibility of wind resources and solar glare, Flat A was finally selected for the discussion of 
the impact of building height and window operation modes.

\section{Building height}

The height of flats in high-rise buildings can cause differences of cooling load via the climatic factors. The ambient temperature and wind speed change in line with building height. Flat $\mathrm{A}$ was taken as an example to quantitatively illustrate the impacts. The accumulated cooling load of the cooling ranged $42.9 \sim 52.0 \mathrm{kWh} / \mathrm{m}^{2}$, as shown in Figure 8. The relationship between the floor number of flats and their cooling load was obvious. The cooling load decreased with the increasing floor number in all four modes of window operation.

In addition, preference to natural ventilation strengthened the impact of building height on cooling load. For instance, in case 4 , where the windows are always kept half open throughout the whole day, flats at higher floor can benefit more than in case 1 . The difference of cooling load between Floor 3 and Floor 39 in case 1 and case 4 increased from $4.1 \mathrm{kWh} / \mathrm{m}^{2}, 8 \%$ to $5.7 \mathrm{kWh} / \mathrm{m}^{2}, 12 \%$. The reason is that flats at higher floor with higher wind speed can introduce more fresh air. In this simulation experiment, the up limit outdoor air temperature of window opening was set as $26^{\circ} \mathrm{C}$, and the thermostat temperature of cooling was set as $26^{\circ} \mathrm{C}$. Natural ventilation through window opening will then provide free-cooling opportunities for the flat and the higher the flat is the more free-cooling hours it has.

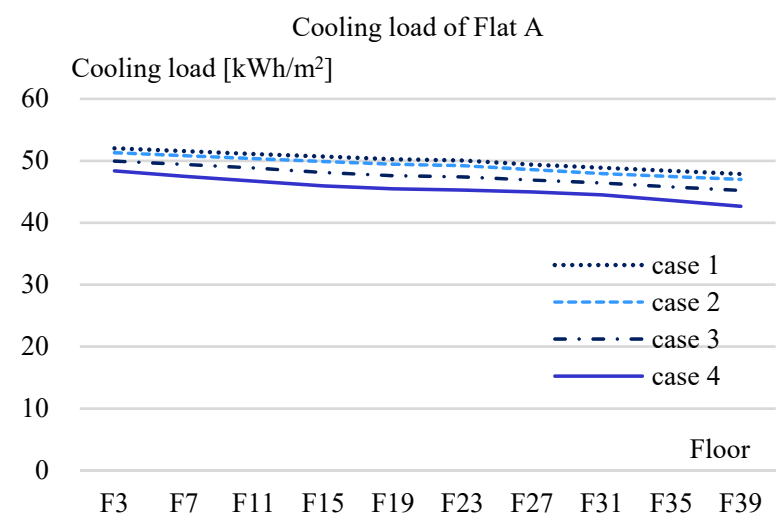

Figure 8: Cooling load by building height

\section{Window operation modes}

Four typical window operation modes were simulated in the energy model, different in available hours of opening windows. The four cases are described in Table 1 and windows can be open when the outdoor air temperature is below $26^{\circ} \mathrm{C}$ during the available hours.

Result of Flat A was shown in Figure 9. The more frequently the windows open, the less the cooling load was. For instance, with the increase of window operation hours, from case 1 to case 4, the cooling load of Flat A at Floor 3 decreased from $52.0 \mathrm{kWh} / \mathrm{m}^{2}$ to $48.4 \mathrm{kWh} / \mathrm{m}^{2}$, showing a difference of $7 \%$.

The building height also enlarged the impact of window operation modes on cooling load. A difference of $11 \%$ was observed between the cooling load of Flat A at
Floor 39 in case 1 and case 4, higher than the $7 \%$ difference at Floor 3. The two factors, the higher floors and longer window operation hours, mean more fresh air into the flat and in this simulation experiment serve as a free cooling source.

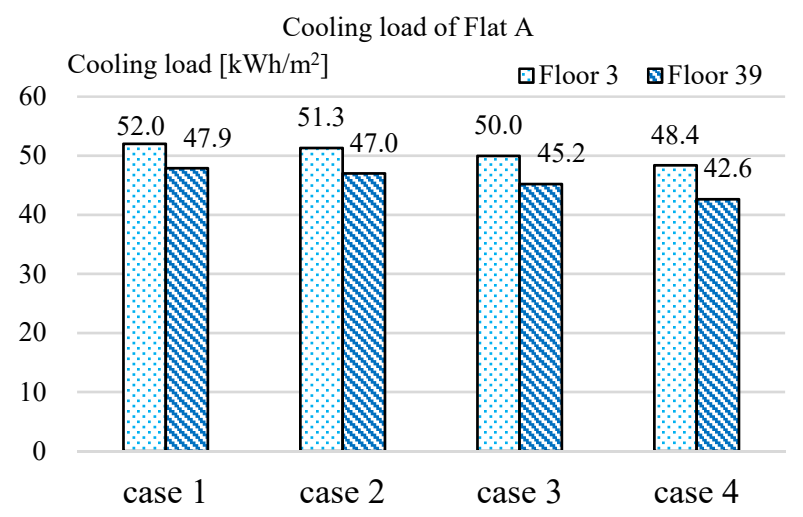

Figure 9: Cooling load by window operation modes

As a summary of the results, the three factors, building height, window operation modes and orientation, can separately lead to a noticeable difference (about 10\%) of cooling load when other two factors are controlled. Firstly, in flats in an orientation where they can take advantages of wind sources, the impact of the other two factors are more obvious. Secondly, there is a negative relationship between cooling load and the building height. The higher the flat is, the less cooling load the flat has. The same is true with window operation modes. The more the occupants open windows, the less cooling load their flat has. Thirdly, it is interesting that the impacts of window operation modes and the building height are enlarged by each other. The target Building X is $125 \mathrm{~m}$ high and the microenvironment surrounding the building is different between lower floors and higher floors, especially the climatic parameters relating to window opening. The results from the energy model of the high-rise Building $X$ thus showed a strengthened impact of window operation modes up to $11 \%$.

\section{Discussion}

The case study of the typical $125 \mathrm{~m}$-high residential building examined the impact of window operation modes on cooling load during the long cooling season in Hong Kong. Previous research also discussed the impact of window opening on cooling load or cooling energy. A building energy simulation of a low-rise office in Jeddah, in a hot and humid climate, reported an up to about $20 \%$ hourly saving on cooling energy in summer, with an window open grade of $10 \%$ (Bayoumi, 2017). Another research in Brazil, observed a difference of $12 \%$ in energy consumption for cooling in a low-rise household caused by different window operation modes. In January with the peak cooling demand, energy consumption of cooling was simulated as $96.9 \mathrm{kWh} /$ month under automated ventilation and $110.2 \mathrm{kWh} /$ month under night ventilation (Sorgato, Melo, \& Lamberts, 2016).

This paper has advanced the discussion on the window opening from the low-rise buildings to high-rise 
buildings. The interesting fact about high-rise buildings other than low-rise ones is that the benefit of opening windows to save cooling load will be enlarged in highrise buildings. The outdoor air temperature decreases and wind speed increases in line with the building height. The change of microclimate with building height allows windows at higher floors introduce more and cooler fresh air. For instance, in this case study, the difference of accumulated cooling load for Flat A between two conditions, 1) in Floor 3 with no windows open and 2) in Floor 39 with window always open, can be as large as $18 \%$ through out the cooling season.

In addition to directly reducing the cooling load, window opening can even affect cooling load from the interaction with other behaviours of cooling. The exclusive relationships between the operation of windows and air conditioners, were found in the survey. About $88 \%$ occupants would close windows before turning on air conditioners and about $83 \%$ occupants would turn off air conditioners before opening windows. The survey results indicated that occupants generally would not operate windows and air conditioners simultaneously. A new case, namely case 5, displays how much more cooling load is affected by the interaction between the operation behaviours of air conditioners and windows (Figure 10). In case 5, the cooling load produced when windows are open is the not-air-conditioned cooling load. The cooling load to manage in case 5 is thus less than that in case 4 .

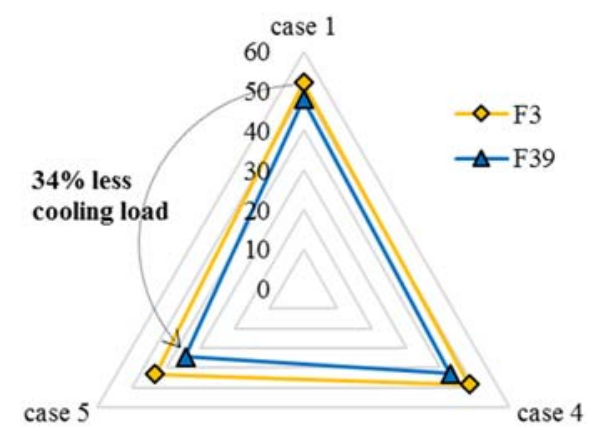

Figure 10: Cooling load of Flat A in case 1,4,5

The cooling load of Flat $A$ at Floor 3 in case $1 / 4 / 5$ was $52.0 \mathrm{kWh} / \mathrm{m}^{2}, 48.4 \mathrm{kWh} / \mathrm{m}^{2}$ and $43.2 \mathrm{kWh} / \mathrm{m}^{2}$, and at Floor 39 was $47.9 \mathrm{kWh} / \mathrm{m}^{2}, 42.6 \mathrm{kWh} / \mathrm{m}^{2}$ and $34.5 \mathrm{kWh} / \mathrm{m}^{2}$, with the largest difference as $34 \%$. All the three incentives, the building height, the window operation modes and the behaviour interactions collaborate with each other and contribute to the observed difference (and Figure 11).

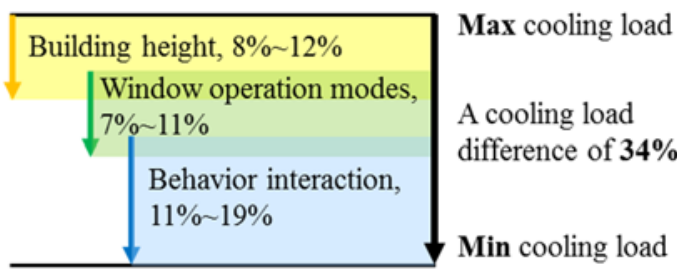

Figure 11: Causes of difference of cooling load
The hourly cooling load in bedroom of Flat A at Floor 3 and Floor 39, during a typical day in cooling season is displayed in Figure 12.

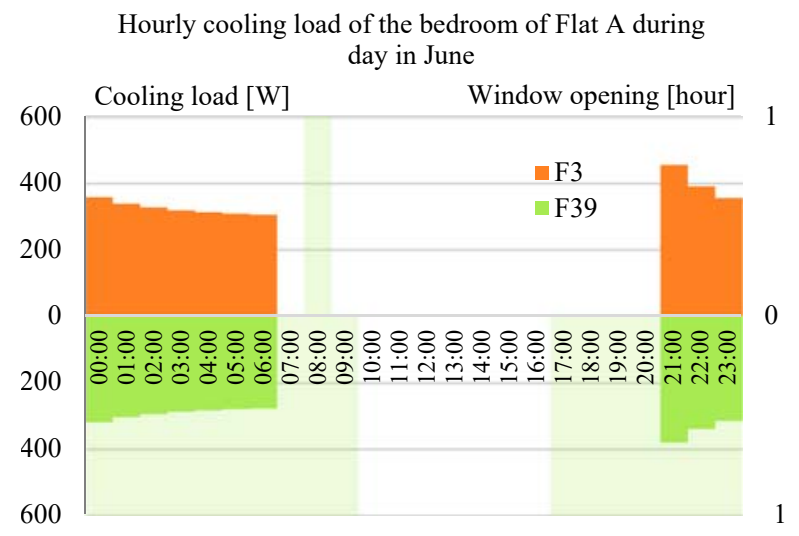

Figure 12: Interaction between behaviours of cooling

The light green area in the chart covers hours when fresh air are introduced into the bedroom. Flat A at Floor 39 has more available hours of window opening than that at Floor 3. Because flats at higher floors are surrounded by cooler ambient environment. As mentioned above, occupants generally would not open windows and turn on air conditioners at the same time. Savings on cooling energy can be achieved in the highlighted hours via the energy-free cooling measure, window opening, other than air conditioning. Especially, both behaviours can provide similar thermal comfort of the indoor environment with proper control strategies. Then it is clear that the factor of building height, window operation modes and behaviour interaction can strengthen the impact on cooling load of the other two factors.

\section{Conclusions}

This paper has examined quantitatively the impact of occupant behaviours of opening windows and operating air conditioners on cooling load in high-rise residential buildings in Hong Kong. The research has been conducted through the building energy simulation supplemented by a carefully designed POE questionnaire survey with the occupants. A number of attributing factors have been identified for the difference of cooling load. There are several conclusions.

Firstly, different occupant behaviour modes in terms of ventilation can cause an up to $11 \%$ variance in cooling load of flats in a high-rise residential building in building energy simulation. Moreover, the more time the accessibility of cool fresh air, the less cooling load the flat has. The most popular window operation mode in residential buildings as shown by the survey, is keeping windows available to open for the whole day. This mode can take best of free cooling resources from ambient environment and then save energy. It is of great meaning to shape a proper behaviour mode of window opening as a quick and cost-free solution for energy efficiency in residential buildings.

Secondly, the building characteristics have notable effect on how much the window operation modes influence the cooling load. The building orientation and the building 
height lead to different climate conditions of flats in a high-rise residential building. Solar and wind resources varied in different flats at one floor, and flats receiving more solar glare and less wind will benefit less from the change of window operation modes. Moreover, outdoor air temperature and wind speed change in line with the building height, and then influence the free cooling opportunities of the flat and finally lead to the differences in energy saving potential. In other words, the building height can enlarge the impact of window operation modes on the cooling load in high-rise buildings. Thus, it is important to carefully consider the climatic parameters of a high-rise building. Using only one set of climate data for all flats in a high-rise building can be risky, especially in research of occupant behaviours and energy consumption variance of households.

Thirdly, the interaction between the operation of windows and air conditioners also contribute to the difference of the cooling load. According to survey results, more than $80 \%$ people would not turn on air conditioners and open windows at the same time, whilst the rest would not be influenced by the operating air conditioners when they want to open windows and vice versa. Cooling load produced during window open hours would probability be not air-conditioned if there were satisfactory and acceptable indoor thermal environment. In addition to directly introducing cool fresh air to reduce the cooling load, proper window opening behaviour modes can also save cooling energy indirectly via coordination with air conditioning behaviours. It is thus of great importance to take good consideration of the exclusive relationships between operation of windows and air conditioners.

The novelty of this paper resides with the scientific consideration for the changing micro climatic conditions along the building height, as well as the dynamic interaction between different occupant behaviours. The conclusions of this paper will inform future research on occupant behaviour in high-rise residential buildings in two aspects.

First, the methodology applied in research on high-rise buildings should be carefully designed according to research objectives. It can be rather different from the methodology used in research on low-rise buildings, such as different climatic inputs and sampling processes. For example, the accuracy of energy modelling would be improved by considering heating energy consumption of individual flats (Jang \& Kang, 2018).

Second, the interaction between behaviours deserves future study. The building energy model of this paper simulated how to obtain thermal comfort with proper combination of active and passive cooling methods. Future study can explore how the environmental factors shape the adaptive behaviours (Sadat Korsavi, Montazami, \& Brusey, 2018). A Long-term observation of occupant behaviours are necessary to collect sufficient and reliable behaviour data to evidence the results of building energy simulation.

\section{References}

Aflaki, A., Mahyuddin, N., \& Baharum, M. R. (2016). The influence of single-sided ventilation towards the indoor thermal performance of high-rise residential building: A field study. Energy and Buildings, 126, 146-158. doi:https://doi.org/10.1016/j.enbuild.2016.05.017

Balvedi, B. F., Ghisi, E., \& Lamberts, R. (2018). A review of occupant behaviour in residential buildings. Energy and Buildings, 174, 495-505. doi:https://doi.org/10.1016/j.enbuild.2018.06.049

Bayoumi, M. (2017). Impacts of window opening grade on improving the energy efficiency of a façade in hot climates. Building and Environment, 119(Supplement C), 31-43. doi:https://doi.org/10.1016/j.buildenv.2017.04.008

Bethlehem, J. (2009). Applied Survey Methods A Statistical Perspective. Hoboken: Wiley.

Chan, A. L. S., Chow, T. T., Fong, S. K. F., \& Lin, J. Z. (2006). Generation of a typical meteorological year for Hong Kong. Energy Conversion and Management, 47(1), 87-96. doi:https://doi.org/10.1016/j.enconman.2005.02.01 $\underline{0}$

CLP. (2017). Residential Tariff. Retrieved from https://www.clp.com.hk/en/Documents/tariff2017/ TariffTable en2017-01-01.pdf

Du, J., \& Pan, W. (2018). Understanding energy related occupant behavior in high-rise residential buildings in Hong Kong. Paper presented at the The 4th Asia Conference of International Building Performance Simulation Association, Hong Kong, China.

EEO, \& EMSD. (2017). Energy Saving Tips for Home. Retrieved from https://www.emsd.gov.hk/filemanager/en/content 718/Energy_Saving Tips for_Home.pdf

Electrical and Mechanical Services Department. (2018). Code of Practice for Energy Efficiency of Building Services Installation.

EMSD. (2018). Hong Kong Energy End-Use Data (2018). Retrieved from https://www.emsd.gov.hk/filemanager/en/content 762/HKEEUD2018.pdf

Hong Kong Observatory. (2018). Upper-air Weather Measurements. Retrieved from https:/www.hko.gov.hk/out photo/upper-airweather.htm

Hong, T., Taylor-Lange, S. C., D’Oca, S., Yan, D., \& Corgnati, S. P. (2016). Advances in research and applications of energy-related occupant behavior in buildings. Energy and Buildings, 116, 694-702. doi:https://doi.org/10.1016/j.enbuild.2015.11.052

IEA, \& IPEEC. (2015). Building Energy Performance Metrics. Retrieved from 9, rue de la Fédération, 75739 Paris cedex 15, France: http://www.iea.org/publications/freepublications/pu blication/BuildingEnergyPerformanceMetrics.pdf

Jang, H., \& Kang, J. (2018). An energy model of highrise apartment buildings integrating variation in 
energy consumption between individual units. Energy and Buildings, 158, 656-667. doi:https://doi.org/10.1016/j.enbuild.2017.10.047

Leeuw, E. D. d., Hox, J. J., \& Dillman, D. A. (2008). International Handbook of Survey Methodology.

Lotfabadi, P. (2014). High-rise buildings and environmental factors. Renewable and Sustainable Energy Reviews, 38, 285-295. doi:https://doi.org/10.1016/j.rser.2014.05.024

Ng, E., Yuan, C., Chen, L., Ren, C., \& Fung, J. C. H. (2011). Improving the wind environment in highdensity cities by understanding urban morphology and surface roughness: A study in Hong Kong. Landscape and Urban Planning, 101(1), 59-74. doi:https://doi.org/10.1016/j.landurbplan.2011.01.0 $\underline{04}$

Sadat Korsavi, S., Montazami, A., \& Brusey, J. (2018). Developing a design framework to facilitate adaptive behaviours. Energy and Buildings, 179, 360-373.

doi:https://doi.org/10.1016/j.enbuild.2018.09.011

Simone, M. D., Carpino, C., Mora, D., Gauthier, S., Aragon, V., \& Harputlugil, G. U. (2018). Reference procedures for obtaining occupancy profiles in residential buildings. Retrieved from https://annex66.org/sites/default/files/2018FinalRe port $/$ Subtask $\% 20 \mathrm{~A} \% 20$ Deliverable $\% 20$ -

$\% 20$ Reference $\% 20$ procedures $\% 20$ for $\% 20$ obtaining \%20occupancy $\% 20$ profiles $\% 20$ in $\% 20$ residential $\%$ 20buildings.pdf

Sorgato, M. J., Melo, A. P., \& Lamberts, R. (2016). The effect of window opening ventilation control on residential building energy consumption. Energy and Buildings, 133(Supplement C), 1-13. doi:https://doi.org/10.1016/j.enbuild.2016.09.059

Stazi, F., Naspi, F., \& D'Orazio, M. (2017). A literature review on driving factors and contextual events influencing occupants' behaviours in buildings. Building and Environment, 118, 40-66. doi:https://doi.org/10.1016/j.buildenv.2017.03.021

Thompson, S. K. (2012). Sampling (3rd ed.). Hoboken: John Wiley \& Sons, Inc. 